\title{
Comparative effect of intraoperative propacetamol versus placebo on morphine consumption after elective reduction mammoplasty under remifentanil-based anesthesia: a randomized control trial [ISRCTN7 I 723 I73]
}

Michèle Binhas*, François Decailliot, Saïda Rezaiguia-Delclaux, Powen Suen, Marc Dumerat, Véronique François, Xavier Combes and Philippe Duvaldestin

Address: Service d'Anesthésie-Réanimation, Hôpital Henri Mondor, AP-HP, Université Paris XII, 51, avenue du Maréchal de Lattre de Tassigny, 94010 Créteil, France

Email: Michèle Binhas* - michele.binhas@hmn.ap-hop-paris.fr; François Decailliot - francois.decailliot@hmn.ap-hop-paris.fr; Saïda RezaiguiaDelclaux - saida.rezaiguia-delclaux@hmn.ap-hop-paris.fr; Powen Suen - po-wen.suen@hmn.ap-hop-paris.fr;

Marc Dumerat - marc.dumerat@hmn.ap-hop-paris.fr; Véronique François - veronique.francois@hmn.ap-hop-paris.fr;

Xavier Combes - xavier.combes@hmn.ap-hop-paris.fr; Philippe Duvaldestin - philippe.duvaldestin@hmn.ap-hop-paris.fr

* Corresponding author

Published: 14 September 2004

BMC Anesthesiology 2004, 4:6 doi:10.1 I86//47/-2253-4-6

This article is available from: http://www.biomedcentral.com/I47/-2253/4/6

(C) 2004 Binhas et al; licensee BioMed Central Ltd.

This is an open-access article distributed under the terms of the Creative Commons Attribution License (http://creativecommons.org/licenses/by/2.0), which permits unrestricted use, distribution, and reproduction in any medium, provided the original work is properly cited.
Received: 05 March 2004

Accepted: 14 September 2004

\begin{abstract}
Background: Postoperative administration of paracetamol or its prodrug propacetamol has been shown to decrease pain with a morphine sparing effect. However, the effect of propacetamol administered intra-operatively on post-operative pain and early postoperative morphine consumption has not been clearly evaluated. In order to evaluate the effectiveness of analgesic protocols in the management of post-operative pain, a standardized anesthesia protocol without long-acting opioids is crucial. Thus, for ethical reasons, the surgical procedure under general anesthesia with remifentanil as the only intraoperative analgesic must be associated with a moderate predictable postoperative pain.
\end{abstract}

Methods: We were interested in determining the postoperative effect of propacetamol administered intraoperatively after intraoperative remifentanil. Thirty-six adult women undergoing mammoplasty with remifentanil-based anesthesia were randomly assigned to receive propacetamol $2 \mathrm{~g}$ or placebo one hour before the end of surgery. After remifentanil interruption and tracheal extubation in recovery room, pain was assessed and intravenous titrated morphine was given. The primary end-point was the cumulative dose of morphine administered in the recovery room. The secondary end-points were the pain score after tracheal extubation and one hour after, the delay for obtaining a Simplified Numerical Pain Scale (SNPS) less than 4, and the incidence of morphine side effects in the recovery room.

For intergroup comparisons, categorical variables were compared using the chi-squared test and continuous variables were compared using the Student $t$ test or Mann-Whitney $U$ test, as appropriate. A $p$ value less than 0.05 was considered as significant.

Results: In recovery room, morphine consumption was lower in the propacetamol group than in the placebo group $(p=0.0 \mathrm{I})$. Pain scores were similar in both groups after tracheal extubation and lower in the propacetamol group $(p=0.003)$ one hour after tracheal extubation. The time to reach a SNPS $<4$ was significantly shorter in the propacetamol group $(p=0.02)$. The incidence of morphine related side effects did not differ between the two groups.

Conclusions: Intraoperative propacetamol administration with remifentanil based-anesthesia improved significantly early postoperative pain by sparing morphine and shortening the delay to achieve pain relief. 


\section{Background}

Postoperative administration of paracetamol or its prodrug propacetamol has been shown to decrease pain with a morphine sparing effect [1-4]. The effect of propacetamol administered intraoperatively on postoperative pain and early postoperative morphine consumption has not been clearly evaluated. However, for a predictable moderate postoperative pain, intraoperative administration of nonopioid analgesics such as paracetamol and postoperative intravenous administration of morphine are recommended in patients undergoing general anesthesia with remifentanil [5]. Indeed, remifentanil differs from potent mu agonists by its extremely short elimination half-life [6]. The elimination kinetics of remifentanil is so fast that its analgesic effect wears off abruptly, thus making the management of postoperative pain critical.

In order to evaluate the effectiveness of intraoperative paracetamol administration in the management of postoperative pain and morphine consumption, a standardized anesthesia protocol without long-acting opioid is necessary. Thus, for ethical reasons, the surgical procedure under general anesthesia with remifentanil as the only intraoperative analgesic must be associated with a moderate predictable postoperative pain.

Therefore, the present study was designed to evaluate the effect of intraoperative administration of propacetamol during remifentanil-based anesthesia on postoperative pain in patients undergoing reduction mammoplasty.

\section{Methods \\ Patients}

After approval by the Local Ethical Committee and written informed consent, 36 consecutive female patients who underwent elective reduction mammoplasty were included. Exclusion criteria were the preoperative use of analgesic drugs; a body mass index $\geq 35$, an American Society of Anesthesiology physical status $\geq 3$ and sensitivity to paracetamol. Pain evaluation using a Simplified Numerical Pain Scale (SNPS) was explained to the patients during the preoperative anesthetic visit and the day before surgery. A standardized surgical technique was used for all patients.

\section{Anesthetic protocol}

Hydroxyzine $2 \mathrm{mg}^{\mathrm{kg}}{ }^{-1}$ was given orally $12 \mathrm{~h}$ and $2 \mathrm{~h}$ before anesthesia as premedication. Before induction of anesthesia, patients were randomly allocated to either Placebo group or Propacetamol group. Randomization was based on computer-generated codes maintained in sequentially numbered, opaque envelopes. The preparation of the propacetamol or saline infusion was done by a nurse who was not in charge of the patient. The anesthetist, the patient and the nurse's staff caring for the patients in the recovery room were unaware of the treatment group. In both groups, anesthesia was induced with propofol $2.5 \mathrm{mg} \cdot \mathrm{kg}^{-1}$ followed by a slow bolus $(1 \mathrm{~min})$ of remifentanil $1 \mathrm{mcg} \cdot \mathrm{kg}^{-1}$. Tracheal intubation was facilitated by atracurium $0.5 \mathrm{mg} . \mathrm{kg}^{-1}$. Anesthesia was maintained with remifentanil 0.1 mcg.kg-1. $\mathrm{min}^{-1}$ and isoflurane $\left(0.5-1.0 \%\right.$ end-tidal) with nitrous oxide $\left(\mathrm{N}_{2} \mathrm{O}\right)$ in $50 \%$ oxygen. Remifentanil infusion rate was increased or decreased by $0.05 \mathrm{mcg} . \mathrm{kg} . \mathrm{min}^{-1}$ in order to maintain an arterial systolic pressure of $20 \%$ more or less than the baseline value. One hour before the end of surgery, which corresponded to the beginning of the skin closure, patients received either propacetamol $2 \mathrm{~g}$ in $50 \mathrm{cc}$ saline (Propacetamol group) or $50 \mathrm{cc}$ saline alone (Placebo group) infused over $10 \mathrm{~min}$. At the end of surgery, administration of isoflurane and $\mathrm{N}_{2} \mathrm{O}$ were withdrawn and the patient was transferred in the recovery room. The anaesthetist, the patient and the nurse's staff caring for the patients in the recovery room were unaware of the treatment group. Remifentanil infusion was interrupted when the patient arrived in recovery room. Tracheal extubation was performed within a few minutes after remifentanil discontinuation. Clinical monitoring included heart rate, blood pressure, pulse oxymetry, respiratory rate, and sedation score (0: awake, 1: drowsy and 2: asleep).

From the time of extubation, pain was evaluated on using a SNPS (from 0 , no pain to 10 the worse pain) and intravenous $2 \mathrm{mg}$ morphine was administered on request every 5 min until pain relief (SNPS $<4$ ). When pain relief was reached, SNPS was subsequently evaluated every $15 \mathrm{~min}$. Morphine was interrupted when the sedation score went up to 1 , systemic arterial pressure $<80 \mathrm{mmHg}$ or respiratory rate less than $8 / \mathrm{min}$. During the data collection period, intravenous morphine titration was further administered if SNPS was up to 4 . Patients did not receive antiemetic prophylaxis. If post-operative nausea and vomiting (PONV) occurred, metoclopramide $10 \mathrm{mg}$ and ondansetron $4 \mathrm{mg}$ if necessary were intravenously administered.

Patients fulfilling Aldrete criteria [7] were discharged from recovery room.

\section{Measurements}

Morphine requirement, pain and sedation scores were measured every $5 \mathrm{~min}$ until pain relief was obtained. When SNPS was below 4 during $15 \mathrm{~min}$, parameters were subsequently recorded every $15 \mathrm{~min}$. Morphine side effects (nausea, vomiting, urinary retention, shivering and itching) and need for supplemental medications (e.g., antiemetics) were also recorded.

The total dose of morphine in recovery room was the primary end point. Pain scores after extubation and one hour 
after tracheal extubation, delay for morphine requirement, delay for pain relief and incidence of morphine side effects were recorded.

\section{Statistical analysis}

Data are expressed as mean ( \pm standard deviation) for quantitative variables normally distributed, or otherwise as median (25th - 75th percentiles) when data were not normally distributed, and as percentage for categorical variables. Data were analyzed using Statview 5.0 software (SAS Institute Inc, USA). For intergroup comparisons, categorical variables were compared using the chi-squared test and continuous variables were compared using the Student t test or Mann-Whitney U test, as appropriate. A $p$ value less than 0.05 was considered as significant. Anticipating a standard deviation of 2.49 [8], it was calculated that 15 patients at least were necessary to show a difference between groups in morphine consumption of $4 \mathrm{mg}$ (considered as a clinically relevant difference) with a $80 \%$ power and a 5\% type 1 error.

\section{Results}

Thirty-six patients were included during a 12 months period: 19 in Propacetamol group and 17 in Placebo group (Table 1). There was no significant difference between the groups concerning clinical characteristics, anesthesia duration and total amount of remifentanil administered. In all patients, extubation was obtained within $7 \pm 3$ min (Table 1 ) after remifentanil discontinuation.

In recovery room, cumulative morphine consumption was significantly lower in the Propacetamol group than in the Placebo group (Table 2). Five minutes after extubation, pain scores were similar in both groups (SNPS $=6$ ). Pain scores one hour after tracheal extubation were significantly lower in the Propacetamol group than in the Placebo group (Table 2). Moreover, the time to reach a SNPS score less than 4 was significantly shorter in Propacetamol group compared to the Placebo group. All the patients received intravenous morphine titration in the first hour after extubation and three patients (one in Placebo group and two in Propacetamol group) required a morphine titration over one hour after extubation. Once a SNPS value less than 4 was obtained, pain scores remained stable and similar in both groups except in one patient in Placebo group who required an additional $2 \mathrm{mg}$ intravenous bolus of morphine 80 min after extubation.

The incidence of morphine adverse effects was similar in both groups: 5 patients had nausea ( 3 in Propacetamol and 2 in Placebo group, $\mathrm{p}=\mathrm{NS}$ ) and 4 patients had vomiting ( 2 in each group, $\mathrm{p}=\mathrm{NS}$ ), no other side effects were observed. In one patient receiving placebo, morphine titration was interrupted because of nausea and vomiting.

\section{Discussion}

This study shows that propacetamol administered one hour before end of surgery reduced the morphine dose given over the first four postoperative hours and shortened the elapsed time to obtain a SNPS under 4 in patients undergoing elective reduction mammoplasty. In our study, surgical technique and anesthetic protocol were similar in both groups. Remifentanil was the only analgesic used during anesthesia period and was interrupted before morphine administration. Thus, the beneficial effect on postoperative pain observed is clearly linked to intraoperative administration of propacetamol.

In a recent study [9], Verchère and colleagues failed to demonstrate a postoperative analgesic effect of intraoperative propacetamol administration, after remifentanil anesthesia for supratentorial craniotomy. Pain after supratentorial neurosurgery was too severe and paracetamol was insufficient to relief it. In our study mammoplasty was chosen because postoperative pain is moderate [10], and intravenous administration of morphine was used in recovery room. Thus, the morphine sparing effect of intraoperative administration of paracetamol could be really evaluated with respect of ethical requirement.

Our results are apparently at variance with those of other previous studies. Paracetamol given rectally immediately after induction of anesthesia [11] or at the end of gynecological surgery [12] and orally before surgery [13-16] failed to improve early postoperative analgesia. The negative results of these studies may be ascribable to several causes such as the low initial pain score in the control group $[11,12,15,17]$, and the difference in the route used for paracetamol administration [11-16]. An other hypothesis to consider is the use of long-acting opioid such as fentanyl that might have contributed to the early postoperative analgesia $[14,18]$.

Cobby and colleagues observed a morphine sparing effect when paracetamol $1.3 \mathrm{~g}$ was administered rectally at the end of hysterectomy [19]. One explanation is that plasma concentration after $1.3 \mathrm{~g}$ paracetamol was sufficient to achieve opioid sparing effect comparable with that of intravenous propacetamol. This hypothesis is strengthened by the results of another trial showing that after rectal administration of a high dose of paracetamol (40 and $60 . \mathrm{mg} \mathrm{kg}^{-1}$ ) pain score and analgesic demand were significantly reduced in the early postoperative period [20].

The presently observed incidence of postoperative nausea and vomiting was of $25 \%$ and was similar to that of a previous study [21]. Despite the reduced dose of postoperative morphine in the Propacetamol group, the incidence of postoperative nausea and vomiting was not dimin- 
Table I: Demographic characteristics and perioperative parameters.

\begin{tabular}{|c|c|c|}
\hline & Placebo Group $(n=17)$ & Propacetamol Group $(n=19)$ \\
\hline Age (years) & $4 I(16)$ & $34(14)$ \\
\hline Body mass index $\left(\mathrm{kg} \cdot \mathrm{m}^{-2}\right)$ & $26(4)$ & $25(3)$ \\
\hline Duration of anesthesia (min) & $245(55)$ & $245(80)$ \\
\hline Remifentanil consumption $\left(\mu \mathrm{g} \cdot \mathrm{kg}^{-1} \cdot \mathrm{min}^{-1}\right)$ & $0.150(0.055)$ & $0.155(0.040)$ \\
\hline Final intraoperative corporeal temperature (Celsius) & $36.8(0.4)$ & $36.7(0.5)$ \\
\hline Delay before extubation after remifentanil interruption $(\mathrm{min})$ & $7(3)$ & $7(3)$ \\
\hline
\end{tabular}

Data are expressed as mean (standard deviation) for age, body mass index, final intraoperative corporeal temperature and delay before extubation. Other data are expressed as median (interquartile).

Table 2: Postoperative intravenous morphine requirement and pain scores in recovery room.

\begin{tabular}{|c|c|c|c|}
\hline & Placebo Group $(n=17)$ & Propacetamol Group $(n=19)$ & $p$ value \\
\hline Morphine consumption in recovery room (mg) & $16[8-34]$ & $10[6-28]$ & 0.01 \\
\hline $\begin{array}{l}\text { Delay between extubation and first morphine administration } \\
(\min )\end{array}$ & $5[5-20]$ & $5[5-15]$ & NS \\
\hline SNPS score five minutes after extubation & $6[0-9]$ & $6[0-10]$ & NS \\
\hline SNPS score one hour after extubation & $3[2-6]$ & $2[0-4]$ & 0.003 \\
\hline Delay between extubation and obtaining a SNPS score $<4(\mathrm{~min})$ & $40[20-85]$ & $30[15-70]$ & 0.02 \\
\hline
\end{tabular}

Data are expressed as median [25th $-75^{\text {th }}$ percentile]. $\mathrm{P}<0.05$ was considered as statistically significant. Pain score was evaluated on using a Simplified Numerical Pain Scale (SNPS: from 0, no pain to 10 the worse pain).

ished. Our results are in agreement with the recent study of Aubrun and co-workers [4] who observed that postoperative intravenous propacetamol allowed a morphinesparing effect but did not reduce the incidence of morphine-related adverse effects in patients undergoing general surgery.

Propacetamol was administered at the beginning of skin closure, which corresponds to one hour before the end of surgery. This delay may be insufficient to achieve pain control immediately after tracheal extubation, as the peak effect of intravenous propacetamol was shown to occur only two hours after its administration [22]. Nevertheless, we considered that it was not feasible to administer propacetamol earlier, as in our practice duration of surgery was unpredictable.

In summary, intraoperative propacetamol administration in women undergoing reduction mammoplasty improved significantly early postoperative pain in recovery room, and should be recommended for postoperative pain management.

\section{References}

I. Delbos A, Boccard E: The morphine sparing effect of propacetamol in orthopaedic post-operative pain. I Pain Symptom Manage 1995, 10:279-86.
2. Hyllested M, Jones S, Pedersen JL, Kehlet $\mathrm{H}$ : Comparative effect of paracetamol, NSAID or their combination in postoperative pain management: a qualitative review. $\mathrm{Br} J$ Anaesth 2002, 88:199-2।4

3. Romsing J, Moiniche S, Dahl JB: Rectal and parenteral paracetamol, and paracetamol in combination with NSAIDs, for postoperative analgesia. $\mathrm{Br} J$ Anaesth 2002, 88:2I 5-26.

4. Aubrun F, Kalfon F, Mottet $P$, Bellanger A, Langeron $O$, Coriat $P$ : Adjunctive analgesia with intravenous propacetamol does not reduce morphine-related adverse effects. $\mathrm{Br} J$ Anaesth 2003, 90:314-9.

5. Albrecht S, Schuttler J, Yarmush J: Postoperative pain management after intra-operative remifentanil. Anesth Analg 1999, 89:S40-5.

6. Glass PS, Gan TJ, Howell S: A review of the pharmacokinetics and pharmacodynamics of remifentanil. Anesth Analg 1999, 89:S7-14.

7. Aldrete JA, Kroulik D: A post anesthetic recovery score. Anesth Analg 1970, 49:924-34.

8. Rosaeg OP, Bell M, Cicutti NJ, Dennehy KC, Lui AC, Krepski B: Preincision infiltration with lidocaine reduces pain and opioid consumption after reduction mammoplasty. Reg Anesth Pain Med 1998, 23:575-9.

9. Verchere E, Grenier B, Mesli A, Siao D, Sesay M, Maurette P: Postoperative pain management after supratentorial craniotomy. J Neurosurg Anesthesiol 2002, 2:96-101.

10. Bonica J: Postoperative pain. In The management of pain Edited by: Bonica J. Philadelphia: Lea and Febiger; 1990:46I-80.

II. Bremerich D, Neidhart G, Heimann K, Kessler P, Behne M: Prophylactically-administered rectal acetaminophen does not reduce post-operative opioids requirements in infants and small children undergoing elective cleft palate repair. Anesth Analg 200I, 92:907-I2.

12. Hein A, Jakobsson J, Ryberg G: Paracetamol I g given rectally at the end of minor gynaecological surgery is not efficacious in reducing post-operative pain. Acta Anaesthesiol Scand 1999, 43:248-5I. 
13. Gustafsson I, Nyström E, Quiding H: Effect of preoperative paracetamol on pain after oral surgery. Eur J Clin Pharmacol 1983, 24:63-5.

14. Cade L, Ashley J: Prophylactic paracetamol for analgesia after vaginal termination of pregnancy. Anaesth Intensive Care 1993, $21: 93-6$.

15. Watcha MF, Ramirez-Ruiz M, White PF, Jones MB, Lagueruela RG, Terkonda RP: Perioperative effects of oral ketorolac and acetaminophen in children undergoing bilateral myringotomy. Can J Anaesth 1992, 39:649-54.

16. Bennie RE, Boeringer LA, Mc Mahon S, Allen H, Dierdorf SF: Postoperative analgesia with preoperative oral ibuprofen or acetaminophen in children undergoing myringotomy. Paediatr Anaesth 1997, 7:399-40.

17. Kalso $\mathrm{E}$ : Better standardisation will improve the quality of analgesic studies. Acta Anaesthesiol Scand 1996, 40:397-8.

18. Jackobsson J, Rane K: Anaesthesia for short outpatient procedures. A comparison between thiopentone and propofol in combination with fentanyl or alfentanil. Acta Anaesthesiol Scand 1995, 39:503-7.

19. Cobby TF, Crighton IM, Kyriakides K, Hobbs GJ: Rectal paracetamol has a significant morphine-sparing effect after hysterectomy. Br J Anaesth 1999, 83:253-6.

20. Korpela R, Korvenoja P, Meretoja O: Morphine-sparing effect of acetaminophen in pediatric day-case surgery. Anesthesiology 1999, $91: 442-7$

21. Marley R: Postoperative nausea and vomiting: the outpatient enigma. J Perianesth nursing 1996, I I:| |47-6I.

22. Piguet $\mathrm{V}$, Desmeules J, Dayer P: Lack of acetaminophen ceiling effect on RIII nociceptive flexion reflex. Eur J Clin Pharmacol 1998, 53:32I-4.

\section{Pre-publication history}

The pre-publication history for this paper can be accessed here:

http://www.biomedcentral.com/1471-2253/4/6/prepub
Publish with Biomed Central and every scientist can read your work free of charge

"BioMed Central will be the most significant development for disseminating the results of biomedical research in our lifetime. "

Sir Paul Nurse, Cancer Research UK

Your research papers will be:

- available free of charge to the entire biomedical community

- peer reviewed and published immediately upon acceptance

- cited in PubMed and archived on PubMed Central

- yours - you keep the copyright 